\title{
Analytical Tools for Monitoring Arsenic in the Environment
}

\author{
J.H.T. Luong ${ }^{*}$ E. Majid and K.B. Male
}

Biotechnology Research Institute, National Research Council Canada, Montreal, Quebec, Canada H4P 2R2

\begin{abstract}
Inorganic arsenic possesses the highest toxicity threat amongst all its forms found in natural groundwater and its mobility in aquatic systems and in the soil is of great environmental concern. Besides their toxicity to humans, arsenate and arsenite are highly toxic to plants. Arsenic can only be transformed into a less-toxic material and becomes a permanent part of the environment. Thus, there is a continuing need for its monitoring at arsenic-containing sites where it occurs naturally at elevated levels. This report reviews technologies with the potential to measure and monitor arsenic in the environment. However, we focus on the modern electrochemical methods of arsenic detection in drinking water. The pros and cons of such techniques are discussed with respect to their sensitivity, ability to detect the chemical states of arsenic, reliability, potential interferences, and ease of operation. In particular, emphasis has been devoted to more recent topics including modern stripping voltammetry, electrode modification, nanomaterials, and biosensors. The necessity for field instrumentation, detection and monitoring has also been addressed.
\end{abstract}

\section{INTRODUCTION}

Odorless and tasteless arsenic in ground water supplies has attracted much attention due to its wide occurrence in Bangladesh, India, Inner Mongolia, China, and many other countries. This toxic element is unevenly distributed in the earth's crust in soil, rocks, and minerals and ranked twentieth in abundance of elements in the earth's crust $(\sim 1.8 \mathrm{mg}$ $\left.\mathrm{kg}^{-1}\right)$ [1]. Arsenic occurs as a major constituent in more than 200 minerals, including elemental As, arsenides, sulfides, oxides, arsenates and arsenites. Arsenopyrite (FeAsS), realgar $\left(\mathrm{As}_{4} \mathrm{~S}_{4}\right)$ and orpiment $\left(\mathrm{As}_{2} \mathrm{~S}_{3}\right)$ are the most important of these minerals [2]. Arsenic is one of the most toxic elements encountered in the environment. Arsenic is also a major component of the thermal water with a concentration up to $47 \mathrm{mg} / \mathrm{L}$ (ppm) in carbonaceous chloride mineral springs [3]. Arsenic enters lakes, rivers, or underground water when mineral deposits or rocks containing arsenic dissolve. Arsenic is then released to soil, surface water, groundwater, and the atmosphere with other metals including $\mathrm{Cu}, \mathrm{Pb}, \mathrm{Ag}$, and $\mathrm{Au}$. Arsenic is also a by-product of some agricultural and industrial activities such as the burning of waste and fossil fuels (especially coal), gold and base metal mining, or agricultural use of pesticides and feed additives. Although industrial use of arsenic has decreased in recent years, it remains a significant source for human health problems.

Arsenic exists in four valency states: $\operatorname{As}(-\mathrm{III}), \operatorname{As}(0)$, $\mathrm{As}(\mathrm{III})$ and $\mathrm{As}(\mathrm{V})$ with oxidized $\mathrm{As}(\mathrm{III})$ and $\mathrm{As}(\mathrm{V})$ as the most widespread forms in nature. Under reducing conditions arsenite, $\mathrm{As}(\mathrm{III})$ is the dominant form existing as arsenious acids $\left(\mathrm{HAsO}_{3}{ }^{2-}, \mathrm{H}_{2} \mathrm{AsO}_{3}{ }^{-}\right.$and $\left.\mathrm{H}_{3} \mathrm{AsO}_{3}\right)$ whereas in oxygenated environments arsenate, $\mathrm{As}(\mathrm{V})$ is normally the stable form existing as arsenic acids $\left(\mathrm{H}_{2} \mathrm{AsO}_{4}{ }^{-}, \mathrm{HAsO}_{4}{ }^{2-}\right.$, and $\mathrm{AsO}_{4}{ }^{3-}$ ). Arsenic forms bonds with organic sulfur, nitrogen, and carbon. As(III) reacts with sulfur and sulfhydryl groups such as cystine, organic dithiols, protein and enzyme, but it does not react with amine groups or organics with reduced

*Address correspondence to this author at the Biotechnology Research Institute, National Research Council Canada, Montreal, Quebec, Canada H4P 2R2; E-mail: John.Luong@enrc-nrc.gc.ca nitrogen constituents. In contrast, $\mathrm{As}(\mathrm{V})$ reacts with reduced nitrogen groups such as amines, but not sulfhydryl groups. Carbon forms organoarsenicals with both the trivalent and pentavalent forms. As $(\mathrm{V})$, is a form of As with many industrial/commercial applications such as agricultural pesticides, glass manufacturing, $\mathrm{Cu}$ refining and the prevalent form in soils under oxidizing conditions [4]. As(III) is expected to be the primary form of As encountered in waste environments and water-saturated soils or soils with significant organic matters. The complexation of arsenic (III and V) with dissolved organic matters in the environment prevents sorption and co-precipitation with solid-phase organics and inorganics. Therefore, the mobility of arsenic in aquatic systems and in the soil is of great environmental concern [5].

According to the World Health Organization, there is an urgent need to develop simple, reliable, sensitive, and inexpensive equipment for field measurement. This report reviews technologies with the potential to measure and monitor arsenic in the environment. However, we focus on the modern electrochemical methods of arsenic detection in drinking water.

\section{TOXICITY OF ARSENIC}

An estimated 65 million Bangladeshis are exposed to poisoning through drinking water, since the ground level arsenic concentration in some locations reaches as high as 2 $\mathrm{mg} / \mathrm{L}(2 \mathrm{ppm})$ [6]. Arsenite is about $50 \%$ of the total arsenic $(10-1000 \mathrm{ppb})$ in the groundwater of many wells in West Bengal (India), whereas As(III) was found to be the dominant form of the total arsenic (400-800 ppb) with a ratio of 2.6:1 over $\operatorname{As}(\mathrm{V})$ in Taiwan [7]. In addition, the people in such countries often use this water for crop irrigation resulting in the introduction of arsenic in the food chain through various plants including rice. The World Health Organization (WHO) as well as the US Environmental Protection Agency (EPA) has set the arsenic standard for drinking water at $10 \mathrm{ppb}$ and water systems had to comply with this standard by January 23, 2006 to protect the public [8]. In the United States, Western states have more systems with arsenic levels greater than $10 \mathrm{ppb}$. The standard is based on lifetime exposure to arsenic from drinking water, and takes into 
account the ability to measure arsenic and to remove it from drinking water supplies. Unfortunately, this standard cannot be met by some developing countries where the old standard of $50 \mathrm{ppb}$ is still considered as an acceptable level mainly because of economical factors. Surprisingly, as many as 56 million people in the US have consumed water with arsenic at unsafe levels [9]. In Canada, arsenic levels in Canadian drinking water are below $5 \mathrm{ppb}$, although concentrations might be higher in some areas.

After swallowing, arsenic in drinking water is absorbed and distributed in the bloodstream. The human body gets rid of arsenic mostly through urine, with smaller amounts removed through the skin, hair, nails, and sweat. The highest levels of arsenic are found in nails and hair, which accumulate arsenic over time. Like many contaminants that enter drinking water supplies, arsenic is potentially hazardous at high levels. Short-term exposure (days/weeks) to very high levels of arsenic in drinking water can result in abdominal pain, vomiting and diarrhea; muscular cramping or pain, weakness and flushing of skin, skin rash; numbness, burning or tingling sensation or pain in hands and feet; thickening of the skin on the palms of the hands and soles of the feet; or loss of movement and sensory responses [10]. Long-term exposure (over many years or decades) to high levels of arsenic in drinking water may also cause: thickening and discoloration of the skin; nausea and diarrhea; decreased production of blood cells; abnormal heart rhythm and blood vessel damage; or numbness in the hands and feet [10]. Arsenicosis is a chronic disease with a significant latency period for non-cancer and cancer effects. Arsenite enters cells at neutral $\mathrm{pH}$ by aquaglyceroporins (glycerol transport proteins) in bacteria, yeast, and mammals and its toxic effect is a result of its ability to bind sulfhydryl groups of cysteine residues in proteins, resulting in protein inactivation [11]. The organic arsenic species abundant in seafood are readily eliminated by the body, thus being much less harmful to health. According to the World Health Organization (WHO), there is an urgent need to develop simple, reliable, sensitive, and inexpensive equipment for field measurements. Inorganic compounds consist of water-soluble arsenite (As(III)), the most toxic form and arsenate $(\mathrm{As}(\mathrm{V}))$, the less toxic form. Arsenite is about 10 times more toxic and mobile [12] than arsenate and 70 times more toxic than the two methylated species: dimethylarsinate and monomethylarsonate. Arsenobetaine and arsenocholine are virtually non-toxic. However, low risk arsenic (V) compounds can be readily converted back into As(III) by bacterial and other environmental activities [13]. Besides their toxicity to humans, arsenate and arsenite are highly toxic to plants because they uncouple phosphorylation and inhibit phosphate uptake. At higher concentrations, arsenic interferes with plant metabolic processes and inhibits growth and under severe conditions, it may lead to plant death [13].

Electroanalysis is adaptable for field assays, relatively inexpensive, and can produce a large number of screening results in a short time. The electroanalytical use of microfabricated arrays with a well-defined and reproducible geometry has increased. These arrays offer several benefits, such as low noise level, sensitivity, cost efficiency, and applicability for use in field portable or in-situ instrumentation. Unlike colorimetric field kits, electrochemical techniques can yield precise quantitative data when careful analytical methods are followed. In groundwater, arsenic is predominantly present as As (III) and As (V), together with a minor amount of methyl and dimethyl arsenic compounds [14]. Therefore, it is of priority importance to develop methods for the selective determination of $\mathrm{As}(\mathrm{III})$ and $\mathrm{As}(\mathrm{V})$. In this review, we examine current analytical procedures with a focus on the electrochemical methods for inorganic arsenic species, i.e., total As, As (III) and As (V).

\section{ANALYTICAL PROCEDURES FOR MEASUREMENT OF ARSENIC}

Accurate measurement of arsenic in drinking water requires expensive and sophisticated instrumentation and facilities as well as trained staff. These techniques include; atomic absorption spectroscopy (AAS), atomic fluorescence spectrometry, inductively coupled plasma (ICP), ICP/mass spectrometry (MS), and LC/MS/MS. Such techniques provide limits of detection well below the WHO arsenic guideline $(10 \mathrm{ppb})$, but are lab-based instrumentation. They are also time consuming and not suitable for routine monitoring of large numbers of samples.

-Hydride Generation: Perhaps, this is the most popular sample derivatization method for inorganic arsenic detection. Field kits have been used extensively to test for arsenic in groundwater, and in many cases, it is the only assay applied. The current baseline methodology involves a variety of technologies that are all variations of the "Gutzeit" method, developed over 100 years ago [15]. In brief, sodium or potassium tetrahydroborate is used for arsine production as $\mathrm{NaBH}_{4}$ and $\mathrm{KBH}_{4}$ are both reliable reducing reagents [16]. This procedure can differentiate As (III) from As (V) since As (III) reacts with tetrahydroborate at a higher $\mathrm{pH}$ than $\mathrm{As}$ (V). However, transition metals might interfere with the determination of arsenic, due to the reaction of the interfering transition metal ions with the $\mathrm{NaBH}_{4}$ reductant. L-cysteine is very useful for preventing iron interferences.

Most of the commercial kits use zinc powder as a reducing agent for As (V) and As (III) to arsine $\left(\mathrm{AsH}_{3}\right)$ which passes through or over a piece of paper impregnated with mercuric bromide to form mixed arsenic/mercury bromides $\left(\mathrm{AsH}_{2} \mathrm{HgBr}\right)$ [16].

$$
\begin{aligned}
& \mathrm{As}_{4} \mathrm{O}_{6}+12 \mathrm{Zn}+24 \mathrm{H}^{+} \rightarrow 4 \mathrm{AsH}_{3} \text { (gas) }+12 \mathrm{Zn}^{2+}+6 \mathrm{H}_{2} \mathrm{O} \\
& \mathrm{Zn}+2 \mathrm{H}^{+} \rightarrow \mathrm{Zn}^{2+}+\mathrm{H}_{2} \text { (gas) }
\end{aligned}
$$

The color change from white to yellow to brown is compared with a calibrated color scale or transferred into a digital readout. The limiting step, hydride generation reaction, varies from 10 to $30 \mathrm{~min}$, depending upon reagents used. Sulfur, selenium, and tellurium compounds are potential interferents. The Dupont oxidizing agent Oxone ${ }^{\circledR}$ is added prior to arsine generation to overcome possible interferences from hydrogen sulfide, which creates grey spots on the paper. Alternatively, the generated arsines are passed through a piece of paper impregnated with lead acetate before they reach the mercuric bromide reagent [17]. The best reported limit of detection with these kits is $2 \mathrm{ppb}$. However, data obtained by the field kits do not corroborate well with laboratory methods, especially when the estimation is based on color visualization. This inexpensive method can be easily handled by minimally trained personnel. However, it cannot detect monomethylarsonate and dimethylarsinate. The assay 
generates toxic mercury solid waste and highly toxic arsine gas, well above the threshold limiting value of $0.05 \mathrm{ppm}$ by volume recommended by the Occupational Safety and Health Administration [18].

-Test Kits: To date, most field test kits detect high levels of arsenic but are unreliable at lower concentrations (less than $100 \mathrm{ppb}$ ) of concern for human health. As discussed, these kits based on the classical Gutzeit test, involve the reduction by zinc of arsenite and arsenate to arsine gas, which then is used to produce a stain on mercuric bromide paper or silver diphenyl dithiocarbamate. Although these tests are much less expensive (US\$0.5/sample) compared to ICP (US\$8$10 /$ sample) $33 \%$ of the measurements would have been considered as false negative, particularly in the range below 70 ppb. Beginning in 1997, the World Bank, WHO, and other international agencies used field kits extensively to test local groundwater wells [19]. Arsenite ion electrochemically reduced into arsine gas [20], compared favorably to reduction by the chemical reducing agent sodium borohydride. The arsine gas reacted with a silver compound to give a highly colored complex that can be measured quantitatively with a detection limit of $50 \mathrm{ppb}$. However, gold, copper, and iron (III) species present in the sample interfere with the sample reduction. Arsine can bleach a dye in a solution containing detergents and metal particles to provide detection for arsenic as low as $30 \mathrm{ppb}$. Arsine gas can pass through a permeable membrane and is then oxidized to arsenate and transformed into its molybdenum complex. With this method, 15 $\mathrm{ppb} \mathrm{As}(\mathrm{V})$ can be detected from unfiltered samples without interference from phosphate, nickel, copper, and iron, which interfere with the molybdenum blue assay as well as the conventional SW-846 laboratory analytical method [21].

-ICP: The plasma atomizes and ionizes all forms of arsenic so that the response does not vary with species as in the more traditional AAS methods. ICP is often used together with MS or AES (Atomic Emission Spectroscopy). The ICPMS technique provides higher precession and lower detection limits. Sample introduction via electrothermal vaporization should be used to overcome plausible interference from high levels of chloride due to the formation of argon chloride in the plasma (the same mass as arsenic, 75As). However, it is still problematical for the determination of low concentrations of arsenic in "real-world" samples due to the poor ionization efficiency in ICP. Detailed information on this subject can be found elsewhere [22]. Several reports on the determination of arsenic in water have appeared since the first report of this method in 1993 [23].

-Neutron Activation Analysis (NAA): The decay of target nuclides in the sample with a definite half-life, upon activation with formation of radioactive nuclides, emits beta particles and gamma rays which can be detected by a NAA high-resolution gamma-ray spectrometer. As one of the most sensitive analytical techniques, NAA is often used as a reference method. However, spectral interferences are encountered, possibly owing to a high salt level in sea water [24]. This problem might be overcome by using $\mathrm{Pb}(\mathrm{NO})_{3}$ and $\mathrm{TiCl}_{3}$ as the carrier and reducing agent.

-Capillary Electrophoresis (CE): In combination with a sensitive detection technique, $\mathrm{CE}$ using a 50-75 $\mu \mathrm{m}$ diameter fused silica capillary has potential as an analytical technique. Under an applied separation potential, charged analytes are separated based upon differential migration rates. CE has been used to detect arsenic by direct absorbance of the arsenic species with detection limits in the ppm range whereas indirect laser-induced florescence detection shows detection limits for arsenic in the range of $250 \mathrm{ppb}$ [25]. However, with indirect UV, detection limits below $1 \mathrm{ppb}$ can be achieved. A recent study developed miniaturized detection devices using isotachophoresis [26]. A microfabricated chip (8-cm long, $8-\mathrm{cm}$ wide and 6-mm thick) is fabricated and fitted with a conductivity detector with a detection limit of 2 and $5 \mathrm{ppm}$ for arsenite and arsenate, respectively. The size, durability, and ease of use make $\mathrm{CE}$ a strong candidate for sensor technologies, provided greater sensitivity can be achieved with other detection schemes.

-Laser-induced Breakdown Spectroscopy (LIBS): This technique can determine the elemental composition of aerosols, liquids, gases, and solids qualitatively and quantitatively in real time with a single laser pulse. A high-powered, pulsed laser beam is focused directly into the targeted sample to form a small laser-induced breakdown, called a laser spark. The resulting high-temperature plasma is sufficient to vaporize, atomize, and electronically excite a small amount of the sample matter. The electrons within these atoms gain energy, and subsequently emit light at characteristic wavelengths as the plasma cools and the electrons relax to their original condition (i.e., ground state). Speciation is not possible because the technique vaporizes the sample arsenic and due to its poor detection limit (400 ppm), considerable research needs to be done to improve the detection limits for arsenic [27].

-Atomic Force Microscopy (AFM): AFM uses a microcantilever, coated with a "detector film" that interacts with the desired species. The adsorption of a target analyte onto the film causes one of several changes: surface stress, a temperature change, or increased mass. These surface changes all result in the microcantilever deforming (bending). This technology has been applied for the detection of chromate and cesium [28, 29]. These sensors all demonstrated excellent sensitivity, capable of ppb detection limits, and high selectivity. It may be possible to design a coating capable of selectively binding arsenic. Microcantilevers have been fabricated in array for multiple sensing applications.

-Surface Enhanced Raman Spectroscopy (SERS): Raman spectroscopy identifies and quantitates the concentration of molecules by measuring the wavelength and intensity of the laser light scattering. A molecule is adsorbed onto a metal surface (usually silver), and laser light is reflected off the adsorbed molecule. The change in wavelength of the scattered light is dependent on the vibrational spectrum of a target molecule. Raman spectra of arsenite and arsenate in solution are known, although minimum detection limits have not been determined. However, a sensor that uses cationiccoated silver particles as substrates to detect perchlorate, chromate, dichromate, and cyanide anions has been developed. The coating attracts the anions to the SERS substrate where they are identified and quantified by their characteristic Raman scattering. The technique is able to detect chromate anions to levels of $60 \mathrm{ppb}$ [30]. This technology can be miniaturized with recent advances in laser and microfabrication, therefore, SERS technology can be a serious contender 
provided good sensitivity and selectivity for arsenic compounds can be attained.

\section{ELECTROCHEMICAL PROCEDURES}

Electrochemical detection techniques may provide an attractive alternative due to their ease of portability and lowcost instrumentation. Low-cost electrochemical methods include; polarographic techniques, cathodic stripping voltammetry (CSV) and anodic stripping voltammetry (ASV). All of the above techniques are applicable for the determination of As(III). The sample with As(III) can be effectively preserved in hydrazinium chloride and kept refrigerated in order to prevent its oxidation to electro-inactive $\mathrm{As}(\mathrm{V})$. Otherwise, arsenite will be converted to arsenate within 6 days. There are some conflicting results concerning the preservation of As(III) in ascorbic acid. For the determination of total and/or speciation of arsenic in water sample, $\mathrm{As}(\mathrm{V})$ must be reduced to As(III). Several procedures have been developed to address this issue. The most popular reductant potassium iodide, must be used together with ascorbic acid to prevent the oxidation of iodide to triiodide by air. Notice that the reduction only occurs in a strong acidic media and potassium iodide can be used with tin chloride or sodium sulfite. Other reductants are mercaptoacetic acid and L-cysteine. As(V) can be reduced to As(III) by heating the sample with concentrated hydrochloric acid and $48 \%$ hydrobromic acid at 95 $100^{\circ} \mathrm{C}$ for $45 \mathrm{~min}$. Another procedure involves heating $\mathrm{As}(\mathrm{V})$ with sodium sulfite $\left(\mathrm{Na}_{2} \mathrm{SO}_{3}\right)$ in concentrated acid solutions (1 M hydrochloric acid or $1 \mathrm{M}$ perchloric acid).

-Polarography (Linear Sweep Voltammetry (LSV) at the Hanging Mercury Drop Electrode (HMDE)): Unfortunately, LSV, the oldest electrochemical method for the determination of trace inorganic metals provides poor detection limits due to high capacitive currents [31-33]. Differential pulse polarography (DPP) reduces capacitive currents and thus improves the detection limit. However, DPP is still not sensitive enough for the determination of arsenic in water [14]. Polarography is an outdated technique for arsenic determination due to its low sensitivity for arsenic detection at low concentrations in drinking water. Differential pulse polarography yields better sensitivity, however, is associated with less selectivity. These techniques usually involve the utilization of a mercury dropping electrode which itself can pose a toxicity threat to the user involved. Arsenic is not as soluble in mercury as other trace metals such as $\mathrm{Sb}, \mathrm{Pb}, \mathrm{Cd}$ etc. and therefore provides a weaker signal when it is anodically stripped using DPP [34]. Other polarographic techniques for arsenic determination include ac/dc polarography, oscillography [35], square wave polarography [36], rapid linear sweep polarography [32], etc. They are performed under acidic conditions in perchloric, hydrochloric, nitric and sulfuric acids or a combination of two. Typical limits of detection range between $10 \mathrm{ppb}$ and several $\mathrm{ppm}$. Due to the availability of more sensitive electrochemical methods for arsenic detection only a few articles have been published utilizing DPP since the early 1990s. These include work by P. Sharma [37] for the sequential trace determination of $\mathrm{As}(\mathrm{III})$ and $\mathrm{As}(\mathrm{V})$ using DPP for industrial waste water analysis with a detection limit of $10 \mathrm{ppb}$. E. O. Reyes-Salas [38] performed a simultaneous detection of $\mathrm{Ni}, \mathrm{Co}, \mathrm{Sb}$, and As in a mining aqueous sample with a detection limit of 1.4 ppm for arsenic.
-Cathodic Stripping Voltammetry (CSV): In principle, stripping analysis provides enhanced sensitivity compared to direct polarography because the analyte is pre-concentrated on the working electrode. CSV of arsenic at the HMDE is based on arsenic pre-concentration in highly acidic media with further scanning in the cathodic direction to obtain a peak due to the formation of arsine. In order to increase sensitivity, intermetallic complexes of arsenic are stripped from HMDE, whereby As (III) reacts with copper or selenium to form the relevant complex, which can be stripped cathodically.

Deposition: $2 \mathrm{As}^{3+}+3 \mathrm{MHg}+6 \mathrm{e}^{-} \rightarrow \mathrm{M}_{3} \mathrm{As}_{2}+3 \mathrm{Hg}$

Stripping: $\mathrm{M}_{3} \mathrm{As}_{2}+12 \mathrm{H}^{+}+12 \mathrm{e}^{-}+3 \mathrm{Hg} \rightarrow \mathrm{AsH}_{3}+\mathrm{H}_{2}+3 \mathrm{MHg}$

where $\mathrm{M}=\mathrm{Se}$ or $\mathrm{Cu}$

As expected from the above scheme, copper interferes with this method, since it is co-deposited at the same potential applied. Copper (II) at a concentration 10 times that arsenic reduces the arsenic peak height by about half. Copper is a common element which is often present in water samples. Adeloju [39] determined As (III) by cathodic stripping potentiometry (CSP) on a glassy carbon mercury film electrode in the presence of copper (II) ions. By using a mercury film electrode with the application of a constant cathodic stripping current, copper interference problems can be overcome, unlike methods for arsenic which utilize gold film electrodes. Detection limits obtained at mercury films electrodes were comparable to the levels accomplished by CSV on a HMDE and to that reported for anodic stripping potentiometric analysis, as addressed shortly, on a gold film electrode. Most cathodic stripping techniques are carried out by using a HMDE, as this electrode does not suffer from the disadvantages of the solid electrodes, including the response as a function of the history or the formation of oxide films. However, anodic stripping of arsenic using a HMDE is not analytically useful due to interference from the oxidation of mercury.

-Anodic Stripping Voltammetry (ASV): This technique for trace arsenic analysis, which is based on the deposition of metal arsenic on the electrode surface with subsequent anodic stripping, is as follows.

$$
\begin{aligned}
& \text { Deposition: } \mathrm{As}^{3+}+3 \mathrm{e}^{-} \rightarrow \mathrm{As}^{0} \\
& \text { Stripping: } \mathrm{As}^{0} \rightarrow \mathrm{As}^{3+}+3 \mathrm{e}^{-}
\end{aligned}
$$

The arsenic oxidation peak appears as a shoulder on the mercury oxidation wave on a HMDE. Different electrode materials including; platinum, gold, mercury, modified glassy carbon (GC), and boron doped diamond have been used for these sensing techniques in combination with a variety of acids such as $\mathrm{HCl}, \mathrm{H}_{2} \mathrm{SO}_{4}, \mathrm{HClO}_{4}$ and $\mathrm{HNO}_{3}$ as supporting electrolyte for the As(III) reduction to elemental As. GC electrodes modified by gold nanoparticles are able to detect arsenic as low as $10 \mathrm{ppt}$ by ASV [40] (linear sweep or square wave). However, the lowest contamination level of As in commercially available $\mathrm{HCl}$ and $\mathrm{HNO}_{3}$ is just below $10 \mathrm{ppt}$ and this could pose an analytical challenge for attempts to detect arsenic around this level. Nevertheless, EPA has already approved analytical method SW-846-7063 for ASV which is capable of measuring from 0.1 to $300 \mathrm{ppb}$ of free (i.e., not adsorbed or bound to any other species in solution) arsenic. 
An Anodic Stripping Voltammetric field apparatus called the Nano-Band ${ }^{\mathrm{TM}}$ Explorer is portable and suitable for field test. A minimum detection limit (MDL) level of $\sim 13 \mathrm{ppb}$ is achieved, but the Nano-Band ${ }^{\mathrm{TM}}$ Explorer requires considerable technical ability. The PDV 6000, another Anodic Stripping Voltammetric field apparatus offers MDL levels of $\sim 7$ $\mathrm{ppb}$. However, some operations require professional judgment. The discontinued Metalyzer ${ }^{\mathrm{TM}} 5000$ instrument can measure multiple toxic metal concentrations in water using the ASV technique with detection limits below ppb levels. However, when arsenic samples are spiked with other common metals at twenty and forty times the analyte concentration, the sensitivity for arsenic detection dramatically decreases. ASV also suffers interference from many species, such as surfactants in water samples.

Microelectrodes offer several advantages for heavy metal analysis by ASV, including a reduced noise level and a high diffusion transfer towards the electrode, eliminating the need for stirring during the concentration step. Arrays of microelectrodes integrated on silicon chips retain the attractive properties of a single microelectrode, while enhancing the sensor response by more than two orders of magnitude [41, 42]. Gold nanoparticles are usually electrodeposited from an acidic gold salt solution onto the glassy carbon (GC) surface by applying a constant potential to the electrode or by continuous cyclic voltammetry $[43,44]$. These systems show good reproducibility and sensitivity. However, electrode performance depends critically on the uniformity and density of the particles. In order to obtain sensitive and reproducible results high quality gold films must be produced by optimizing different parameters that include electrode surface smoothness, deposition potential, deposition time, gold salt concentration etc. In a recent work by Majid et al. [43], gold nanoparticles are deposited on a dual GC electrode within a flow cell setup and used to monitor mineral drinking water samples. A detection limit of $0.25 \mathrm{ppb}$ is reached with good reproducibility within $\pm 1.1 \%$. Stability of the electrode is tested over 40 repetitive injections and long term stability is satisfactory over a one month period. Another study involving flow injection analysis of arsenic includes the work of Zen [45] where a Prussian blue modified screen printed electrode is used with chronoamperometry for the detection. Such systems could play a vital role in online water quality monitoring for trace metals. Nanoparticles have also been deposited on surfaces other than glassy carbon. In one study gold nanoparticles are electrodeposited on to an indium tin oxide coated glass substrate to monitor arsenic in $1 \mathrm{M} \mathrm{HNO}_{3}$ using LSV [46]. In spite of a moderate limit of detection of 5 $\mathrm{ppb}$ and short term stability of several days, these substrates are cost effective to produce and could be used as disposable electrodes in field analysis. Although gold films have been utilized with good success for arsenic determination in drinking water, electrochemical interference by other trace metals has always remained an issue. As an interfering species copper has by far received the most attention. Copper codeposits with arsenic during the deposition step before stripping and can form an intermetallic compound $\mathrm{Cu}_{3} \mathrm{As}_{2}$ as well as metallic copper. The stripping peaks for these species overlap and mask the arsenic peak, decreasing the detection limit depending upon the copper concentration. Chloride interference can also play a role in complicating arsenic de- tection [47]. However, this interference can be avoided by using a different acid instead of $\mathrm{HCl}$.

Platinum nanoparticles have also served as the electrode material with limited success. Dai [48] in a recent study electrodeposited platinum nanoparticles on to a glassy carbon surface for arsenic detection in $1 \mathrm{M} \mathrm{HClO}_{4}$. With a limit of detection of $2 \mathrm{ppb}$ this technique was free from any copper interference. Gold is superior to platinum as a working electrode material due to a higher hydrogen overvoltage, lack of reproducibility is a serious drawback of solid gold electrodes and macro-sized gold film electrodes. To ensure good reproducibility, re-activation of the electrode surface before each measurement is mandatory. The electrode must be re-plated and washed with the sample before each measurement. The formation of hydrogen bubbles during the deposition time also affects reproducibility. A rotating glassy carbon electrode with a gold film or gold rotating disk electrode can be used to remove the hydrogen bubbles [49]. The performance of such a system is dependent upon acidity, deposition time, rotation rate, scan rate, and the electrode reaction. In order to overcome problems commonly encountered by gold macroelectrodes a multiwall carbon nanotube modified gold electrode has been proposed [50]. This was accomplished by modifying carbon nanotubes with thiol groups which where then used to bind the tubes to the gold surface. No apparent interferences and a $0.3 \mathrm{ppb}$ limit of detection were reported. Gold microelectrodes can alternatively be used for arsenic detection. These electrodes are associated with smaller currents, quick steady state attainment, small diffusion layer, less ohmic iR drop, faster response time and higher sensitivity due to enhanced diffusion current per surface area. Salaun [51] reported a sensitive method for the detection of both $\mathrm{As}(\mathrm{III})$ and $\mathrm{As}(\mathrm{V})$ with stripping chronopotentiometry using a $5 \mu \mathrm{m}$ gold microelectrode. Irish seawater, mineral water, and tap water were investigated. The copper peak was detected simultaneously at a more positive shifted potential than arsenic due to the use of a very low $\mathrm{pH}$ of 1 . A limit of detection of $0.2 \mathrm{nM}(0.015 \mathrm{ppb})$ was attained which is more sensitive than ASV methods. High sensitivity can also be attained with gold microelectrodes using hot-wire electrochemistry $[52,53]$. In such systems, the temperature of the electrode is ramped up from room temperature to $60^{\circ} \mathrm{C}$ by a sine-wave power generator connected to the electrode via a high frequency transformer. Signal to noise is reduced and better deposition is achieved by efficient convection near the electrode surface. Heating microwires for hot electrochemistry does not affect the temperature of the bulk solution. A 10 to 15 -fold enhancement was observed with these systems compared to similar setups using rotating disc electrodes. A detection limit of $1 \mathrm{nM}(0.075 \mathrm{ppb})$ was reported. In another attempt to enhance detection sensitivity, arsenic detection was performed under low frequency sound during the deposition step using square wave anodic stripping voltammetry and a gold microdisc electrode [54]. This increased the sensitivity by 50 -fold and decreased the detection limit by 2 orders of magnitude to $3.7 \mathrm{nM}(0.3 \mathrm{ppb})$.

Boron doped diamond (BDD) is a relatively new alternate electrode material for ASV. It offers low background current, a large potential window and long term stability. Bare BDD electrodes have been proven as a suitable electrode substrate for determination of trace metals such as manganese and lead (CSV). Its ASV use for the determina- 
tion of mercury and lead, as well as simultaneous detection of lead and copper and lead and cadmium have also been reported [55, 56]. However, As(III) is not oxidized in the potential window of aqueous solutions at the surface of a bare BDD electrode. Although a detection method with electrogenerated iodine at a BDD electrode in the presence of As(III) is feasible [57], the sensitivity is not very satisfactory. Arsenic (III) detection in $1 \mathrm{M} \mathrm{HCl}$ with a diamond thinfilm electrode modified by co-deposited gold particles provides a sensitivity of $0.01 \mu \mathrm{A} / \mathrm{ppb}$ and linearity ranges from $0.005-40 \mathrm{ppb}[58,59]$. Electrodeposition of gold onto BDD microdisc arrays for arsenic detection has also been investigated [60]. An array of $40 \mu \mathrm{m}$ diameter BDD microdisc electrodes separated from each other by $250 \mu \mathrm{m}$ spacing in a hexagonal fashion was fabricated using vapor deposition techniques. The sensitivity and LOD determined was 1.32 $\mathrm{AM}^{-1}$ and $0.38 \mathrm{nM}(0.028 \mathrm{ppb})$, respectively. These ASV techniques also suffer two major drawbacks: lengthy analysis time (15-20 min for the deposition of arsenite) and severe interference by copper, another common metal found in natural deposits and ground water. These interferences cannot be easily overcome since several metals and ion species can be co-deposited and stripped off under this operating procedure. In addition, the reproducibility of the signal and reusability of the electrode surfaces for these schemes have not been clearly addressed. In a recent study, the interference due to copper and chloride has been overcome by modifying boron doped diamond microelectrodes with platinum nanoparticles and detecting arsenite oxidation to $\mathrm{As}(\mathrm{V})$ by linear sweep voltammetry [61]. This detection device could be used for 150 repetitive runs with a detection limit of 0.5 $\mathrm{ppb}$. Electrochemical etching of platinum allows the reuse of the BDD microelectrode. Iridium-modified, boron-doped diamond electrodes fabricated by an ion implantation method have been developed for electrochemical detection of arsenite (As(III)) [62]. $\mathrm{Ir}^{+}$ions can be implanted with 800 $\mathrm{keV}$ and a dose of $10^{15}$ ions $\mathrm{cm}^{-2}$ followed by an annealing treatment at $850^{\circ} \mathrm{C}$ for $45 \mathrm{~min}$ in $\mathrm{H}_{2}$ plasma ( 80 Torr) to rearrange metastable diamond produced by the implantation process. The electrodes exhibit high catalytic activity toward As(III) oxidation with a detection limit of $20 \mathrm{nM}$ (1.5 ppb). To date, most of the research indicates that it is only possible to directly measure arsenite with ASV; arsenate has to be chemically reduced to arsenite, followed by another ASV measurement since a very high cathodic potential is necessary to reduce $\mathrm{As}(\mathrm{V})$ to $\mathrm{As}^{0}$ (lower than $-0.7 \mathrm{~V}$ vs $3 \mathrm{M}$ $\mathrm{Ag} / \mathrm{AgCl} / \mathrm{KCl}$ ).

\section{BIOSENSORS AND BIOASSAYS}

Many micro-organisms such as algae, fungi, yeast and bacteria have been used for biosorption of toxic elements. As an example, Chlorella vulgaris can transform inorganic arsenic compounds and oxidize As(III) to As(V). The arseniteoxidizing bacteria so far isolated either can gain energy from arsenite oxidation or have been proposed to do so as part of a detoxification process. Aerobic growth with arsenite as the electron donor is exergonic, generating a substantial amount of free energy. Other microorganisms can reduce arsenate to arsenite or even arsine $\left(\mathrm{AsH}_{3}\right)$ whereas marine algae transform arsenate into non-volatile methylated As compounds such as methylarsionic acid and dimethylarsinic acid in seawater. However, this fact has not yet been exploited as a practical way toward the development of a biosensor for As(III) or an analytical system for arsenic speciation.

Arsenite can be oxidized to less toxic arsenate chemically or microbially (As(III) $\mathrm{O}_{2}^{-}+2 \mathrm{H}_{2} \mathrm{O} \rightarrow \mathrm{As}(\mathrm{V}) \mathrm{O}_{4}{ }^{3-}+4 \mathrm{H}^{+}+2 \mathrm{e}^{-}$ ). Chemolithoautotrophic arsenite oxidation, for which oxygen is used as a terminal electron acceptor, arsenite as the electron donor and carbon dioxide as the sole carbon source, has been reported for microorganisms such as Rhizobium sp. strain NT-26 isolated from gold mines [63]. The molybdenum-containing arsenite oxidase from this microorganism is responsible for the oxidation of arsenite to arsenate. The chemolithoautotroph NT-26 oxidizes arsenite to arsenate by using a periplasmic arsenite oxidase. Purification and preliminary characterization of the enzyme reveal that it (i) contains two heterologous subunits, AroA $(98 \mathrm{kDa})$ and AroB (14 kDa); (ii) has a native molecular mass of $219 \mathrm{kDa}$, suggesting a $\alpha_{2} \beta_{2}$ configuration; and (iii) contains two molybdenum and 9 or 10 iron atoms per $\alpha_{2} \beta_{2}$ unit. Very recently, a biosensor has been designed to combine the specificity of the enzymatic oxidation of arsenite oxidase and the sensitivity of electrochemical detection [64]. The enzyme is electrochemically deposited on a multi-walled carbon nanotube modified glassy carbon electrode to form a sensitive and specific biosensor for the analysis of arsenite in contaminated water samples. The resulting biosensor enables direct electron transfer, i.e. effecting reduction and then re-oxidation of the enzyme such that arsenite could be detected in $10 \mathrm{~s}$ with a detection limit of $1 \mathrm{ppb}$ without any interference from copper. Based on an enzyme inhibition assay, an amperometric biosensor to determine As (V) has been developed based on the entrapment of acid phosphatase (AcP) and poly phenol oxidase (PPO) in a single anionic clay layer [65]. Successive hydrolysis of phenyl phosphate into phenol by AcP followed by oxidation of phenol into quinone by PPO constitutes the basic working principle of the sensor. Quinone is detected from the clay layer which is deposited on a glassy carbon electrode. Arsenic concentration is determined by its ability to inhibit the conversion of phenyl phosphate into phenol by AcP. This method can specifically determine As (V) without interference from As (III) or phosphate. A detection limit of $1.5 \mathrm{ppb}$ is established based upon an incubation period of 20 min. Inhibition of acetylcholinesterase by As (III) has also been investigated for arsenic determination [66]. However, the enzyme can be inhibited by other metals and chemicals, therefore this approach is limited to well-defined samples.

Table 1 provides a comparison of the described analytical, electrochemical and biosensor techniques for arsenic analysis with respect to limits of detection (LOD) and general comments regarding advantages, drawbacks and potential interferences. In addition, it is important to take note that sample preparation is a critical step in the analytical procedure used in all of these analytical techniques. Ground water is very clean; therefore, the sample can be processed without or with minimal treatment. However care must be taken to avoid contamination and prevent speciation changes during sample collection and storage. Reducing and oxidizing agents need to be avoided to preserve the oxidation state of the arsenic compounds and ideally plastic containers should be acid washed. Samples should be stored in a refrigerator, however for arsenic speciation studies which cannot be performed within a week, the samples should be frozen until analysis [67]. Samples used with electrochemical detection 
normally need to be acidified and care must be exercised to use acids of extremely high purity to avoid contamination by arsenic from the acid. The most common method for extracting total As from soils and sediments involves wet ashing of the sample using a combination of acids which can be performed with microwave-digestion ovens [68]. In addition the determination of arsenic in solid phases can be performed by a selective sequential extraction (SSE) [69]. SSE has been successfully employed to determine the source of As in the widespread Bangladesh aquifer system [70]. Flow injection (FI) on-line sequential extraction coupled with a detection scheme provides rapid, automatic, and sensitive fractionation of As in soils. The procedure offers several advantages including better accuracy, less sample/reagent consumption, and lower risk of contamination and analyte loss [71] compared with traditional batch-mode sequential extraction.

Conceptually, modern biology techniques can create an arsenic-responsive DNA control sequence and link it to a reporter gene towards the development of an arsenic biosensor. When it is exposed to arsenic compounds, the reporter gene will produce a highly colored material or a fluorescent protein. Although genetically modified microbes are used to develop a set of semi-quantitative assays for potable water, only limited success is achieved for quantifying arsenic. It is not clear whether the microorganisms measure all of the arsenic in a sample or just the bioavailable arsenic. The application of microbes as a biosensor for bioavailable arsenic is the subject of another review. Changes in color pigmentation of two water plants upon exposure to arsenic are another interesting phenomenon. However, more work is required for this "low tech" assay since the coloration changes in plant systems may be due to factors other than arsenic exposure.

\section{CONCLUSIONS}

Arsenic, derived from anthropogenic and geologic sources, has been considered one of the most toxic elements, affecting millions of people who rely on groundwater as drinking water. There is a critical need for the development of reliable and simple methods for arsenic testing in the field or laboratory. Various analytical techniques are available for the determination of arsenic species. Lab-based instrumentation such as ICP-MS and graphite furnace AAS applications provide accurate and reproducible results. The development of newer technology such as AFM and SERS is still in its infancy and they might suffer from high throughput potential and cost issues. X-ray fluorescence can be used for measuring arsenic in biological materials and environmental samples. This method has the advantage that no sample digestion or separation steps are required. However, the sample must be pre-concentrated on a suitable solid substrate such as resin to give a detection limit of 20-50 ppb [72]. Hydride generation combined with atomic fluorescence spectroscopy is a relatively new technique that provides sensitivity better than 20 parts per trillion and linearity up to $10 \mathrm{ppm}$.

Colorimetric assays offer rapid results and are costeffective; however, the reliability and sensitivity remain a critical issue. However, research is still active to improve detection sensitivity. Due to their versatility and miniaturization, electroanalytical techniques have been of great interest in monitoring arsenic contamination on site. To date, electrochemical techniques provide reliable results for fairly clean and well-defined samples in laboratory conditions. However, extensive filed testing and a more rigorous analysis of applicability for environmental measurements remain to be accomplished. Another criticism of using electrochemical methods in the field is electrode fragility. Rugged

Table 1. Some Key Features of Different Analytical Techniques for Analysis of Arsenic

\begin{tabular}{|c|c|c|}
\hline Method & Limit of Detection (LOD) $\mu g L^{-1}(p p b)$ & Comments \\
\hline ICP-AES & 0.7 & $\begin{array}{l}\text { High sensitivity, however equipment is expensive and requiring trained per- } \\
\text { sonnel }\end{array}$ \\
\hline Neutron Activation Analysis & $0.001-0.02$ & High sensitivity, possible spectral interferences \\
\hline Capillary Electrophoresis & $2-5$ & Good sensitivity but requires indirect measurement methods \\
\hline Colorimetric Assays (Gutzeit) & $1-30$ & $\begin{array}{l}\text { Simple, but generates arsine gas and is prone to false positive and false } \\
\text { negative readings }\end{array}$ \\
\hline $\begin{array}{l}\text { Polarography } \\
\text { (LSP, DPP, SQP) }\end{array}$ & 10 & $\begin{array}{l}\text { Poor detection limits, use of toxic mercury and better electrochemistry } \\
\text { techniques now available }\end{array}$ \\
\hline $\begin{array}{l}\text { Cathodic Stripping Voltam- } \\
\text { metry (CSV) }\end{array}$ & 0.5 & $\begin{array}{l}\text { Sensitive, however copper interference a problem and use of mercury a } \\
\text { concern }\end{array}$ \\
\hline $\begin{array}{l}\text { Modified boron doped } \\
\text { diamond (BDD) with } \\
\text { Pt nanoparticles }\end{array}$ & 0.5 & $\begin{array}{l}\text { Sensitive and elimination of interferences by copper and chloride. } \\
\text { Reproducible signal and reusable electrode }\end{array}$ \\
\hline $\begin{array}{l}\text { Arsenite Oxidase based } \\
\text { Biosensor }\end{array}$ & 1.0 & $\begin{array}{l}\text { Sensitive and very selective to } \mathrm{As}(\mathrm{III}) \text {. No interference from copper and fast } \\
\text { analysis time }(10 \mathrm{~s})\end{array}$ \\
\hline $\begin{array}{l}\text { Biosensor } \\
\text { (AcP and PPO) }\end{array}$ & 1.5 & $\begin{array}{l}\text { Sensitive and selective to } \mathrm{As}(\mathrm{V}) \text {, however enzymes can be inhibited by other } \\
\text { metals and chemicals }\end{array}$ \\
\hline
\end{tabular}


field instruments and remote long-term sensors need to be developed and microfabrication and wireless technology could fulfill this requirement.

Arsenic associated with various organic matters, rather than its total concentration affects its mobility, bioavailability, and toxicity. This is another major challenge since the difficulty lies in the extraction of the species from the sample without disturbing equilibrium and changing the physical form. Arsenic cannot be transformed into a non-toxic material and as a permanent part of the environment; there is always a need for its monitoring at elevated levels. Another important issue is the measurement of the amount of arsenic that can be absorbed by a living organism. Although bioavailability will play a strong role in future environmental regulation, the techniques for measuring bioavailable arsenic are varied and the subject of future research endeavor. The field measurements of organoarsenic compounds have not received any attention; perhaps, they are less acutely toxic than inorganic arsenic. As an important fraction of the total environmental arsenic, they should not be discounted.

\section{REFERENCES}

[1] Greenwood, N. N.; Earnshaw, A. Chemistry of the Elements, Pergamon Press: London 1984.

[2] Smedley, P. L.; Kinniburgh, D. G. Applied Geochemistry, 2002, 17, 517.

[3] Baskov, E. A.; Surikov, S. N. Hydrotherms of the Earth Entrails Publ. House: Leningrad 1989.

[4] Turpeinen, R. R.; Panstar-Kallio, M.; Häggblom, M.; Kairesalo, T. Sci. Total Environ., 2002, 285, 133.

[5] EPA 542/R-04/002 2004. Monitoring Arsenic in the Environment: A Review of Science and Technologies for Field Measurements and Sensors.

[6] Environmental Health Criteria 224 (WHO). http://www.inchem. org/documents/ehc/ehc/(Accessed Aug 28, 2007).

[7] Chen, S. L.; Dzeng, S. R.; Yang, M. H.; Chiu, K. H.; Shieh, G. M.; Wai, C. M. Environ. Sci. Technol., 1994, $28,877$.

[8] USEPA 816-F-01-004, Office of Water (4606) 2001.

[9] Natural Resources Defense Council. http://www.nrdc.org/water/ drinking/qarsenic.asp. (Accessed Aug 28, 2007).

[10] Abernathy, C.; Calderson, R. L.; Chappel, W. R. Arsenic Exposure and Health Effects, Elsevier Science Ltd: London 1999.

[11] Kumaresan, M.; Riazuddin, P. Current Science, 2001, 80, 837.

[12] Stronach, S. A.; Walker, N. L.; Macphee, D. E.; Glasser, F. P. Waste Management, 1997, 17, 9 .

[13] Macur, R. E.; Jackson, C. R.; Botero, L. M.; McDermott, T. R.; Inskeep, W. P. Environ. Sci. Technol., 2004, 38, 104.

[14] Hung, D. Q.; Nekrassova, O.; Compton, R. G. Talanta, 2004, 64, 269.

[15] Holak, W. Anal. Chem., 1969, 41, 1712.

[16] Jaunakais, I. Int. Environ. Technol. , 2002, 12, 2.

[17] Durham, N. F.; Kosmus, W. Asian Environ. Technol., 2003, 7, 2.

[18] Hussam, A.; Alauddin, M.; Khan, A. H.; Rasul, S. B.; Munir, A. K. M. Environ. Sci. Technol., 1999, 33, 3686.

[19] Floroiu, R. M.; Davis, A. P.; Torrents, A. Environ. Sci. Technol., 2004, 38, 1031.

[20] Arbab-Zavar; M. H.; Hashemi, M. Talanta, 2000, 52, 1007-1014.

[21] USEPA Test Methods for Evaluating Solid Waste, Physical/Chemical Methods (SW 846). http://www.epa.gov/epaoswer/hazwaste/test/s w846.htm. (Accessed Aug 28, 2007).

[22] USEPA Office of Water, Targeting and Analysis Branch. EPA-815-R-00010, 1999.

[23] Goossens, J.; Moens, L.; Dams, R. J. Anal. At. Spectrom., 1993, 8, 921.

[24] Rottschafer, J. M.; Boczkowski, R. J.; Mark, H. B. Talanta, 1972, $19,163$.

[25] Zhang, P. D.; Xu, G. W.; Xiong, J. H.; Zheng, Y. F.; Yang, Q.; Wei, F. S. J. Sep. Sci, 2002, 25, 1555.

[26] Prest, E. J.; Baldock, S. J.; Fielden, P. R.; Goddard, N. J.; Treves Brown B. J. J. Chrom. A, 2003, 990, 325.
[27] U.S. Department of Energy, Fiber Optic/Cone Penetrometer System for Subsurface Heavy Metals Detection: Innovative Technology Summary Report, 2000.

[28] Ji, H.-F.; Finot, E.; Dabestani, R.; Thundat, T.; Brown, G. M.; Britt, P. F. Chem. Comm., 2000, 457.

[29] Ji, H. F.; Thundat, T.; Dabestani, R.; Brown, G. M.; Britt, P. F.; Bonnesen, P. V. Anal. Chem., 2001, 73, 1572.

[30] Mosier-Boss, P. A.; Lieberman, S. H. Appl. Spec., 2003, 57, 1129.

[31] Lingane, J. J. Ind. Eng. Chem. Anal. Ed., 1943, 15, 583.

[32] Whitnack, G. C.; Brophy, R. G. Anal. Chim. Acta, 1969, 48, 123.

[33] Arnold, J. P.; Johnson, R. M. Talanta, 1969, 16, 1191.

[34] Myers, D. J.; Osteryoung, J. Anal. Chem., 1973, 45, 267.

[35] Underkofler, W. L.; Shain, I. Anal. Chem., 1965, 37, 218.

[36] Hagiwara, K.; Murase, T. Bunseki Kagaku, 1960, 14, 757.

[37] Sharma, P. Anal. Sci., 1995, 11, 261.

[38] Reyes-Salas, E. O.; Dosal-Gomez, M. A.; Barcelo-Quintal, M. H.; Manzanilla-Cano, J. A. Anal. Letts., 2002, 35, 12.

[39] Adeloju, S. B.; Young, T. M.; Jagner, D.; Batley, G. E. Anal. Chim. Acta, 1999, 381, 207.

[40] Dai, X.; Nekrassova, O.; Hyde, M. E.; Compton, R. G. Anal. Chem., 2004, 76, 5924.

[41] Nolan, M. A.; Kounaves, S. P. Anal. Chem., 1999, 71, 3567.

[42] Tercier-Waeber, M. -L.; Pei, J.; Buf, J.; Fiaccabrino, G. C.; KoudelkaHep, M.; Riccardi, G.; Confalonieri, F.; Sina, A.; Graziottin, F. Electroanalysis, 2000, 12(1), 27.

[43] Majid, E.; Hrapovic, S.; Liu, Y.; Male, K. B.; Luong, J. H. T. Anal. Chem., 2006, 78, 762 .

[44] Sun, Y. -C.; Mierzwa, J.; Yang, M. -H. Talanta, 1997, 44, 1379.

[45] Zen, J. -M.; Chen, P. -Y.; Kumar, A. S. Anal. Chem., 2003, 75, 6017.

[46] Dai, X.; Compton, R. G. Anal. Sci., 2006, 22, 567.

[47] Feeney, R.; Kounaves, S. P. Anal. Chem., 2000, 72, 2222.

[48] Dai, X.; Compton, R. G. Analyst, 2006, 131, 516.

[49] Banks, C. E.; Simm, A. O.; Bowler, R.; Dawes, K.; Compton, R. G. Anal. Chem., 2005, 77, 1928.

[50] Profumo, A.; Fagnoni, M.; Merli, D.; Quartarone, E.; Protti, S.; Dondi, D.; Albini, A. Anal. Chem., 2006, 78, 4194.

[51] Salaun, P.; Planer-Friedrich, B.; VanDenBerg, C. M. G. Anal. Chim. Acta, 2007, 585, 312.

[52] Grundler, P.; Flechsig, G. U. Electrochimica Acta, 1998, 43, 3451.

[53] Flechsig, G. U.; Korbutt, O.; Grundler, P. Electroanalysis, 2001, 13, 786.

[54] Simm, A. O.; Banks, C. E.; Compton, R. G. Anal. Chem., 2004, 76, 5051.

[55] Banks, C. E.; Hyde, M. E.; Tomcik, P.; Jacobs, R.; Compton, R. G. Talanta, 2004, 62, 279 .

[56] Compton, R. G.; Foord, J. S.; Marken, F. Electroanalysis, 2003, 15, 1349.

[57] Hignett, G.; Wadhawan, J. D.; Lawrence, N. S.; Hung, D. Q.; Prado, C.; Marken, F.; Compton, R. G. Electroanalysis, 2004, 16, 897.

[58] Song, Y.; Swain, G. M. Anal. Chem., 2007, 79, 2412.

[59] Song, Y.; Swain, G. M. Anal. Chim. Acta, 2007, 593, 7.

[60] Simm, A. O.; Banks, C. E.; Ward-Jones, S.; Davies, T. J.; Lawrence, N. S.; Jones, T. G. J.; Jiang, L.; Compton, R. G. Analyst, 2005, 130, 1303.

[61] Hrapovic, S.; Liu, Y.; Luong, J. H. T. Anal. Chem., 2007, 79, 500.

[62] Ivandini, T. A.; Sato, R.; Makide, Y.; Fujishima, A.; Einaga, Y. Anal. Chem., 2006, 78, 6291.

[63] Santini, J. M.; Sly, L. I.; Wen, A.; Comrie, D.; DeWulf-Durand, P.; Mackay, J. M. Geomicrobiol. J., 2002, 19, 67.

[64] Male, K. B.; Hrapovic, S.; Santini, J.; Luong, J. H. T. Anal. Chem., 2007, DOI: 10.1021/ac070766i.

[65] Cosnier, S.; Mousty, C.; Cui, X.; Yang, X.; Dong, S. Anal. Chem., 2006, 78,4985 .

[66] Stoytcheva, M.; Sharkova, V.; Panayotova, M. Anal. Chim. Acta, 1998, 364, 195.

[67] Gao, S.; Ryu, J.; Tanji, K.K.; Herbel, M.J. Chemosphere, 2007, 67, 862.

[68] Mucci, A.; Boudreau, B.; Guignard, C. Appl. Geochem., 2003, 118, 1011.

[69] Keon, N. E.; Swartz, C. H.; Brabander, D. J.; Harvey, C.; Hemond, H. F. Environ. Sci. Technol. 2001, 35, 2778.

[70] Swartz, C.H.; Blute, N. K.; Badruzzman, B.; Ali, A.; Brabander, D.; Jay, J.; Besancon, J.; Islam, S.; Hemond, H. F.; Harvey, C. F. Geochimica et Cosmochimica Acta, 2004, 68, 4539.

[71] Dong, L.M. and Yan, X.P. 2005. Talanta, 2005, 65, 627.

[72] Driscoll, J. N. Am. Lab. News, 2002, 16. 